\title{
Implementasi Manajemen Kurikulum pada Lembaga Pendidikan Anak Usia Dini
}

\author{
Upik Elok Endang Rasmani ${ }^{1 *}$, Anayanti Rahmawati ${ }^{2}$, Warananingtyas Palupi ${ }^{3}$, \\ Jumiatmoko $^{4}$, Nurul Shofiatin Zuhro ${ }^{5}$, Anjar Fitrianingtyas ${ }^{6}$ iD \\ 1,2.3,4,5,6 Universitas Sebelas Maret, Surakarta, Indonesia. \\ *Corresponding author: upikelok@staff.uns.ac.id
}

\begin{abstract}
Abstrak
Kualitas layanan program pendidikan anak usia dini (PAUD) menunjang keberhasilan peserta didik. Kurangnya pemahaman pendidik mengenai pengelolaan manajemen PAUD terutama manajemen kurikulum menjadi hambatan dalam peningkatan kualitas layanan PAUD. Pengabdian dilakukan dengan tujuan untuk memberikan sosialisasi terkait pelaksanaan dan penataan manajemen kurikulum PAUD khususnya di TK. Manajemen kurikulum sangatlah penting karena manajemen ini menentukan bahan ajar yang disesuaikan dengan aspek perkembangan anak dalam rangka mencapai tumbuh kembang yang optimal dengan pembelajaran yang efektif dan efisien. Pengabdian ini bertujuan untuk memberikan sosialisasi terkait pelaksanaan dan penataan manajemen kurikulum PAUD agar lebih terarah dan berkembang lebih optimal di lembaga PAUD. Sampel pengabdian adalah TK. Hasil pengabdian menunjukkan bahwa pelatihan dan pendampingan berjalan dengan baik meskipun terkendala oleh pandemi, guru TK lebih memahami pengelolaan dan penataan manajemen kurikulum PAUD sehingga dapat mencapai tujuan pendidikan lebih otpimal secara efektif dan efisien. Luaran kegiatan pengabdian ini ialah adanya peningkatan pemahaman dan pelaksanaan manajemen kurikulum PAUD lebih terarah dan berkembang optimal.
\end{abstract}

Kata Kunci: Manajemen, Kurikulum, PAUD

\section{Abstract}

The quality of services for early childhood education programs (PAUD) supports the success of students. The lack of understanding of educators regarding PAUD management, especially curriculum management, is an obstacle in improving the quality of PAUD services. The service is carried out to provide socialization related to the implementation and arrangement of PAUD curriculum management, especially in kindergarten. Curriculum management is very important because this management determines teaching materials that are adapted to aspects of child development to achieve optimal growth and development with effective and efficient learning. This service aims to provide socialization related to the implementation and arrangement of PAUD curriculum management so that it is more focused and develops more optimally in PAUD institutions. The sample of devotion is TK. The results of the service show that the training and mentoring are going well despite being constrained by the pandemic, kindergarten teachers better understand the management and arrangement of PAUD curriculum management so that they can achieve educational goals more optimally effectively, and efficiently. The output of this service activity is an increase in understanding and implementation of PAUD curriculum management, which is more focused and develops optimally.

Keywords: management, curriculum, PAUD

\section{INTRODUCTION}

Pendidikan anak usia dini (PAUD) adalah upaya pembinaan kepada anak yang memiliki usia 0-6 tahun dengan pemberian rangsangan atau stimulasi dalam membantu pertumbuhan dan perkembangan jasmani dan rohani supaya anak memiliki kesiapan dalam memasuki pendidikan lebih lanjut (Ismawati \& Prasetyo, 2021; Rahelly, 2018; Suminah et al., 2015; Watini, 2019). Pendidikan anak usia dini merupakan pendidikan yang menitikberatkan pada peletakan dasar melalui stimulasi dalam membantu pertumbuhan dan perkembangan jasmani dan rohani dengan tujuan anak memiliki kesiapan dalam memasuki pendidikan lebih lanjut. Pada usia tersebut anak dalam masa emas karena potensi yang ada dalam diri anak

$\begin{array}{ll}\text { History: } & \\ \text { Received } & \text { : July 10, } 2021 \\ \text { Revised } & \text { : July 12, } 2021 \\ \text { Accepted } & \text { : August 06, } 2021 \\ \text { Published } & \text { : August 25, } 2021\end{array}$


mengalami pertumbuhan dan perkembangan yang sangat pesat. Pada pendidikan anak usia dini terdapat 6 aspek yang harus dikembangkan yaitu (1) aspek fisik motorik, (2) aspek kognitif, (3) aspek bahasa, (4) aspek seni, (5) aspek sosial emosional, dan (6) aspek nilai, agama, dan moral (Aprinawati, 2017; Halim Yustiyawan et al., 2016; Hasanah, 2015; Hasyim, 2015). Keenam aspek perkembangan tersebut sangatlah penting untuk di stimulasi dengan tepat dan optimal pada anak usia dini karena sangatlah perpengaruh pada pertumbuhan dan pekembangan anak yang lebih optimal.

Kualitas suatu bangsa bergantung pada pendidikan yang dijalani oleh anak-anak pada saat ini terutama pada pendidikan formal salah satunya di PAUD, apa yang diterima oleh anakanak di sekolah, apa yang akan dicapai di sekolah ditentukan oleh kurikulum sekolah. Kualitas pendidikan di taman kanak-kanak sangatlah penting untuk perkembangan anak karena sangat membantu anak untuk sekolah selanjutnya maupun untuk kecakapan hidup anak. Peningkatan pertumbuhan dan perkembangan PAUD terjadi di berbagai wilayah di Indonesia. Namun, pada faktanya peningkatan tersebut tidak sejalan dengan kualitas mutu layanan PAUD yang seharusnya meningkat juga. Masih banyak anak usia dini yang belum mendapatkan layanan program pendidikan yang sesuai dengan tahap perkembangan usianya. Hal ini disebabkan oleh beberapa faktor seperti kurangnya sosialisasi pemerintah dan guru kepada masyarakat mengenai pentingnya program PAUD sehingga pemahaman masyarakat mengenai PAUD minim, rendahnya kualifikasi akademik pendidik dan tenaga kependidikan PAUD, kurangnya pemahaman mengenai pengelolaan manajemen PAUD yang baik dan benar (Aji, 2016; Mertala, 2019). Oleh karena itu pengembangan dan peningkatan lembaga PAUD maupun jumlah pendidik, tenaga kependidikan serta jumlah anak usia dini masih jauh dari jumlah yang diharapkan.

Hal yang sering menjadi permasalahan adalah manajemen kurikulum yang digunakan oleh lembaga PAUD. Pada dasarnya penerapan kurikulum merupakan bagian penting dalam pengembangan kurikulum yang membutuhkan konsep, prinsip, prosedur, dan pendekatan dalam manajemen (Janus \& Brinkman, 2010; Nurdin \& Anhusadar, 2020; Sarinah et al., 2018; Utami et al., 2020). Kurikulum itu sendiri merupakan jantung pendidikan yang harus dikembangkan dan diimplementasikan secara kontekstual dalam rangka memenuhi kebutuhan anak di masa sekarang dan masa mendatang. Kurikulum merupakan pedoman penyelenggaraan kegiatan pembelajaran berupa rencana dan pengaturan mengenai tujuan, isi, dan bahan pelajaran serta cara yang digunakan untuk mencapai tujuan pendidikan (Suminah et al., 2015). Implementasi kurikulum memerlukan ilmu manajemen yang meliputi pelaksanaan, pengorganisasian, koordinasi, motivasi, pengawasan, dan evaluasi yang efektif.

Berdasarkan hasil observasi yang dilakukan, diketahui bahwa permalasahan manajemen PAUD di TK Aulia Suarakarta nampak jelas yaitu berupa sistem manajemen PAUD yang masih belum terstruktur sehingga menyebabkan timbulnya masalah lain salah satunya adalah pembentukan kurikulum yang kurang terarah. Permasalahan tersebut menyebabkan anak-anak tidak dapat menerima layanan sesuai dengan kebutuhan usianya. Lembaga PAUD sangat memerlukan dukungan dari berbagai pihak, baik dari pengelolaan lembaga PAUD itu sendiri maupun dukungan dari pemerintah, masyarakat, dan tentunya orang tua (Ita, 2018). Orang tua wajib terlibat dalam implementasi kurikulum di PAUD karena orang tua merupakan guru pertama bagi anak (Kilile et al., 2019). Keterlibatan tersebut akan sangat membantu perkembangan anak terutama perkembangan aspek sosial emosional. Permasalahan tersebut jika dibiarkan terlalu lama akan berdampak buruk. Maka dari itu diperlukan sebuah solusi, salah satunya ialah dengan melakukan pengabdian. Pengabdian dilakukan dengan tujuan untuk memberikan sosialisasi terkait pelaksanaan dan penataan manajemen kurikulum PAUD khususnya di TK. Pengabdian ini bertujuan untuk menganalisis permasalahan yang ada 
sehingga dapat dibahas bersama-sama dengan para ahli dan menjadi manajemen kurikulum PAUD terarah dan berkembang lebih optimal di lembaga PAUD.

\section{MATERIALS AND METHODS}

Jenis kegiatan yang dilakukan adalah kegiatan pengabdian masyarakat, yang mana kegiatan ini berfokus pada pemahaman dan implementasi manajemen kurikulum PAUD yang terarah dan optimal. Mitra pengadian adalah TK Aulia Surakarta. Pendekatan yang digunakan dalam kegiatan pengabdian masyarakat ini adalah pendekatan kolaboratif, yaitu bekerjasama dengan mitra untuk merencanakan metode, tahap pelaksanaan dan waktu pelaksanaan sosialisasi. Rasib (2016) menjelaskan bahwa pendekatan kolaboratif merupakan pendekatan yang mengutamakan kemitraan pada seseorang atau peserta yang dibimbing untuk menyelesaikan permasalahan yang dihadapi secara kelompok, karena pendapat orang banyak lebih dapat dipertimbangkan dibandingkan dengan pemikiran seorang individu. Tahapan atau langkah-langkah solusi terdiri atas 4 tahapan yaitu langkah ke-1 sosialisasi atau pemaparan ahli. Pemaparan ahli digunakan untuk menyampaikan materi manajemen PAUD berkelanjutan kepada guru meliputi 1) materi tentang manajemen kurikulum PAUD (konsep, fungsi, manfaat, kriteria manajemen kurikulum PAUD); 2) materi tentang pelaksanaan manajemen kurikulum PAUD di sekolah dan praktik langsung dalam menangani masalah yang ada. Langkah ke-2 ialah diskusi. Diskusi digunakan untuk bertukar informasi dan meluruskan pemahaman tentang manajemen kurikulum PAUD. Diskusi dilaksanakan secara menyeluruh yaitu diskusi pemateri dengan peserta dan peserta dengan peserta yang lain. Tujuan diskusi ini agar peserta terdorong untuk berpartisipasi secara optimal, tanpa adanya aturan yang keras namun tetap mengikuti etika yang telah ditetapkan. Langkah ke-3 ialah tanya jawab. Tanya jawab pada kegiatan sosialisasi ini digunakan untuk menegaskan tentang materi manajemen kurikulum PAUD. Langkah ke-4 ialah implementasi. Implementasi digunakan untuk mempraktikkan secara langsung cara dalam membuat penyusunan manajemen kurikulum PAUD. Penyusunan akan dibimbing oleh ahli dan pendamping.

\section{RESULTS AND DISCUSSION}

\section{Hasil}

Program yang dilakukan merupakan hasil kesepakatan antara mitra dan tim pengabdian dengan mempertimbangkan kebutuhan. Pelaksanaan kegiatan diatur dan disesuaikan dengan kegiatan dan waktu kerja dari mitra dan tim pengabdian. Setelah penentuan jadwal, penyusunan kegiatan dilaksanakan dengan menyesuaikan waktu dan metode pelaksanannya. Alur program kegiatan dapat dilihat pada Gambar 1. Pelatihan tersebut berupa pemaparan ahli terkait manajemen kurikulum PAUD oleh ahli, dilanjutkan dengan diskusi dan tanya jawab. Pemaparan tersebut mengenai manajemen kurikulum meliputi perencanaan, pengorganisasian, pengawasan, pelaksanaan, dan evaluasi manajemen kurikulum PAUD. Pada tahap ini, peserta diberi pemahaman mengenai pentingnya perencanaan kurikulum. Perencanaan kurikulum adalah suatu proses dalam menentukan tujuan yang diinginkan dan menentukan bahan dan sumber daya yang dibutuhkan agar efisien dan efektif (Hambali, 2019). Keberhasilan perencanaan tersebut sangatlah berpengaruh pada keberhasilan kegiatan manajemen kurikulum secara keseluruhan (Sarinah et al., 2018). Perencanaan kurikulum tersebut dilaksanakan jauh sebelum pembelajaran berlangsung dan orang tua dari peserta didik juga berpartisipasi dalam perencanaan kurikulum. Hal tersebut juga didukung dengan pernyataan bahwa pendapat orang tua menjadi pertimbangan dan digunakan dalam menentukan tujuan kurikulum dan menjawab kebutuhan masyarakat sesuai dengan kurikulum yang sedang berjalan (Pinyoanuntapong, 2013). Sejalan dengan hal tersebut, orang tua merupakan pemangku kepentingan yang utama 
dalam implementasi kurikulum karena orang tua merupakan guru pertama bagi anak (Kilile et al., 2019). Sependapat dengan hal tersebut, Ruder \& Lohse, (2017) menjelaskan bahwa konsep kurikulum disesuaikan dengan sekolah dan keluarga. Selain dengan pertimbangan orang tua, perencanaan kurikulum juga disesuaikan dengan kurikulum nasional, visi misi sekolah ataupun yayasan, sumber daya manusia, dan anggaran sekolah (Lorente, 2017).

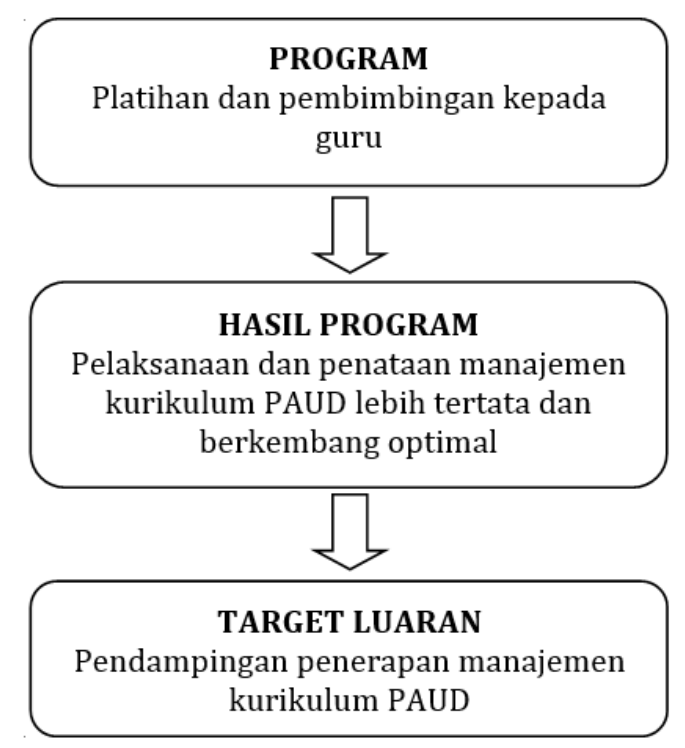

Gambar 1. Alur program kegiatan

Pengorganisasian kurikulum dilakukan oleh kepala sekolah dengan membagi tugastugas yang disesuaikan dengan sumber daya manusia dan sumber bahan pembelajaran yang ada. Pengorganisasian dalam manajemen kurikulum yaitu kepala sekolah mengatur dalam pembagian tugas mengajar, penyusunan jadwal mengajar, dan jadwal kegiatan ekstrakulikuler (Septiani, 2018). Sarinah et al. (2018) menjelaskan bahwa pengorganisasian kurikulum berkiatan dengan bahan pelajaran yang disesuaikan dengan sumber bahan pelajaran yang meliputi nilai sosial, nilai budaya, aspek siswa dan masyarakat, serta ilmu pengetahuan dan teknologi (IPTEK). Ciri-ciri kurikulum yang baik adalah sesuai dengan perkembangan anak, menyeluruh dan mencakup semua aspek perkembangan anak (Suminah et al., 2015). Materi pembelajaran yang digunakan sesuai dengan usia anak. Pembelajaran di kelas berpusat pada anak. Menurut Ekberg et al. (2017) pembelajaran yang sesuai dengan kurikulum dapat mendorong pengalaman yang berpusat pada anak dan berfokus pada kurikulum. Pelaksanaan isi kurikulum dilaksanaan dengan menyesuaikan dengan kurikulum nasional yaitu dengan memperhatikan perkembangan anak. Setiap pelaksanaan pembelajaran mencakup stimulasi aspek nilai, agama, dan moral; fisik motorik; kognitif; bahasa; sosial emosional; dan seni. Pelaksanaan kurikulum meliputi karakteristik kurikulum, strategi implementasi, karakteristik penilaian, pengetahuan guru mengenai kurikulum, sikap dan keterampilan dalam mengarahkan. Perwujudan pelaksanaan kurikulum tersebut tergantung pada kemampuan guru sebagai implementator kurikulum (Sarinah et al., 2018). Pelaksanaan kegiatan pembelajaran di kelas, guru harus memastikan bahwa kegiatan pembelajaran itu mencakup kurikulum yang mendukung lembaga pendidikan (Ekberg et al., 2017). Sumber belajar dan mengajar merupakan bahan yang paling penting dalam memfasilitasi proses pembelajaran oleh bimbingan guru untuk mencapai implementai kurikulum yang efektif dari setiap programnya (Kilile et al., 2019). Pelaksanaan kurikulum juga membutuhkan mitra untuk pengajaran ataupun penyediaan sumber daya di kelas untuk hasil yang berkembang lebih optimal. Menurut 
Sanders-Smith et al., (2021) bahwa pembelajaran di kelas bersama mitra mampu memberikan dukungan tambahan kepada anak-anak di kelas. Selain mitra, orang tua juga memiliki peran dalam memberikan dukungan tambahan kepada anak dengan cara guru memberikan pemahaman mengenai kegiatan yang dapat dilaksanakan di rumah untuk memperkuat tema sesuai yang dilaksanakan di sekolah (Upshur et al., 2019).

Pengawasan pada manajemen kurikulum tersebut bertujuan agar pelaksaan kurikulum sesuai dengan perencanaan dan pengorganisasian yang telah ditetapkan sehingga menghasilkan sesuai yang diharapkan. Pengawasan tersebut mengenai kesesuaian materi dengan kurikulum, keamanan dan kenyamanan peserta didik ketika pembelajaran, dan pembelajaran yang disesuaikan dengan kebutuhan peserta didik. Menurut Halimah (2020) pengawasan merupakan mengendalikan suatu pekerjaan apakah pekerjaan berjalan dengan lancar dan hasil pekerjaan sesuai dengan rencana serta harapan ataulah terdapat halangan dan rintangan dalam pelaksanaan pekerjaan yang harus diperbaiki. Pengawasan kurikulum dapat memotivasi guru dan dapat mengarahkan pada implementasi kurikulum yang efektif (Kilile et al., 2019). Pengawasan yang dilakukan oleh kepala sekolah secara rutin terhadap guru dalam melaksanakan kegiatan pembelajaran sangat berpengaruh pada perkembangan anak karena guru akan termotivasi untuk melaksanakan kegiatan secara benar. Seperti halnya yang dijelaskan oleh (Kilile et al., 2019) dengan pengawasan yang dilakukan secara rutin sangatlah membantu pencapaian anak karena guru akan melaksanakan kegiatan yang benar dan menerapkan kuirkulum dengan cara yang benar sesuai dengan rencana.Pengawasan praktik dalam kelas sehari-sehari meliputi pembelajaran yang sesuai dengan kurikulum dan cara memahami permasalahan di dalam kelas sehingga dapat menjadi bahan evaluasi seperti halnya strategi komunikasi guru di dalam kelas (Sanders-Smith et al., 2021).

Evaluasi pada manajemen kurikulum meliputi analisis kebutuhan dan kelayakan, perencanaan dan pengembangan, proses pembelajaran yang telah dilaksanakanapakah sudah sesuai dengan yang direncanakan untuk dapat menjadi bahan perbaikan pada penyusunan kurikulum selanjutnya. Evaluasi kurikulum merupakan mempertimbangkan kegiatan yang sudah terlaksana apakah sudah sesuai dengan kriteria yang telah disepakati dan dapat dipertanggungjawabkan (Sarinah et al., 2018; Sugiyanto et al., 2015; Suryawan \& Romadi, 2018). Kegiatan evaluasi terdapat hubungan erat antar tiga komponen yaitu tujuan pembelajaran, kegiatan pembelajaran, dan evaluasi. Evaluasi kurikulum dilakukan melalui tahapan evaluasi konteks, input, proses, dan produk.

Setelah pemaparan oleh ahli mengenai manajemen kurikulum PAUD, dilaksanakan sesi diskusi. Diskusi tersebut dilakukan antar peserta dan peserta dengan ahli. Dengan diskusi peserta lebih terbuka dan lebih mudah untuk mengeluarkan ide dan pengetahuan yang ada dalam diri sehingga peserta dapat lebih memahami manajemen kurikulum. Hasil program pelatihan terkait manajemen kurikulum PAUD yaitu peningkatan pengetahuan dan pemahaman terkait pelaksanaan dan penataan manajemen kurikulum PAUD. Pada sesi dikusi peserta dibagi menjadi 4 kelompok. Masing-masing kelompok beranggotakan 3 peserta dan dipandu oleh ahli serta dibantu oleh beberapa mahasiswa. Setiap kelompok membahas mengenai pemahaman manajemen kurikulum PAUD, cara yang selama ini diterapakan dalam melakukan manajemen kurikulum PAUD, strategi yang akan dilakukan untuk melakukan manajemen kurikulum PAUD, dan permasalahan yang dihadapi selama ini dalam pelaksanaan manajemen kurikulum PAUD. Setalah dilaksanakan diskusi dengan kelompok, maka hasil diskusi dibacakan oleh perwakilan setiap kelompok dan dilanjutkan sesi tanya jawab antar peserta dengan ahli. Hal tersebut bertujuan agar peserta memiliki jawaban yang jelas mengenai permasalahan yang dihadapi selama ini serta untuk memberikan penjelasan yang lebih pada peserta yang mengalami ketidakpahaman. Selanjutnya dilaksanakan pendampingan penerapan manajemen kurikulum PAUD sebagai tindak lanjut peningakatan pengetahuan dan mengolahnya menjadi keterampilan penerapan manajemen kurikulum PAUD. 
Hasil program pendampingan dalam penerapan manajemen kurikulum PAUD adalah konsep dan penyusunan kurikulum PAUD yang disesuaikan dengan kebutuhan TK dan kurikulum nasional yang lebih terarah serta lebih optimalnya pelaksanaan manajemen kurikulum PAUD. Partisipasi mitra dalam pengabdian merupakan sebagai pelaku pelatihan. Setelah mengikuti pelatihan, diharapkan mitra dapat memiliki kemampuan dalam pelaksanaan dan penataan manajemen kurikulum yang lebih baik. Hubungan tim pengabdian dan mitra merupakan hubungan konsultatif dan pendampingan. Tim pengabdian secara prakris memotivasi guru agar dapat melaksanakan dan menata manajemen kurikulum PAUD yang lebih optimal sehingga sesuai dengan tujuan dan kebutuhan. Rincian jadwal pelaksanaan kegiatan dapat dilihat pada Tabel 1.

Tabel 1. Rincian jadwal pelaksanaan kegiatan

\begin{tabular}{|c|c|c|c|}
\hline Metode & Pelatihan & Pendampingan & Evaluasi \\
\hline $\begin{array}{c}\text { Observasi dan } \\
\text { wawancara }\end{array}$ & Guru & Guru & Keakuratan informasi \\
\hline Jumlah & 12 & 12 & $\begin{array}{c}\text { Pemahaman manajemen } \\
\text { kurikulum PAUD }\end{array}$ \\
\hline Tempat & $\begin{array}{l}\text { TK Aulia } \\
\text { Surakarta }\end{array}$ & TK Aulia Surakarta & $\begin{array}{c}\text { Perencanaan manajemen } \\
\text { kurikulum PAUD }\end{array}$ \\
\hline Waktu & $\begin{array}{l}\text { Bulan Juni } \\
\text { Pemberian }\end{array}$ & Bulan Juli & Bulan Juli \\
\hline Materi & $\begin{array}{c}\text { materi, diskusi, } \\
\text { tanya jawab } \\
\text { "manajemen } \\
\text { kurikulum } \\
\text { PAUD" }\end{array}$ & $\begin{array}{l}\text { Pelaksanaan dan } \\
\text { penataan manajemen } \\
\text { kurikulum PAUD }\end{array}$ & Draft acuan untuk pelaksanaan \\
\hline Fasilitator & Tim & Tim & Tim \\
\hline
\end{tabular}

Pendampingan yang telah dilakukan selama 2 bulan berjalan dengan lancar. Pada pengabdian ini, terdapat perencanaan, pelaksanaan, dan evaluasi serta kerjasama antara tim pengabdian dan pihak sekolah. Perencanaan yang dilakukan mulai dengan rapat koordinasi dari tim pengabdian dalam rangka persiapan untuk pelaksanaan pengabdian di TK Aulia Surakarta. Selanjutnya melakukan observasi dan wawancara kepada TK Aulia Surakarta yang dilakukan secara daring dalam rangka persiapan pengabdian. Setelah perencanaan sudah matang, pelaksanaan pelatihan dan pendampingan dilakukan serta evaluasi antara tim pengabdian dan pihak sekolah.

Hal yang penting pada kegiatan pengabdian tersebut merupakan gambaran mengenai permasalahan yang dihadapi guru serta kemampuan guru dalam manajemen kurikulum PAUD yang harus diarahkan sehingga tujuan dan manjamen sekolah terutama kurikulum lebih optimal. Manajemen kurikulum yang terarah sangatlah penting karena kurikulum merupakan jantung pendidikan. Kurikulum merupakan pedoman penyelenggaraan kegiatan pembelajaran berupa rencana dan pengaturan mengenai tujuan, isi, dan bahan pelajaran serta cara yang digunakan untuk mencapai tujuan pendidikan (Suminah et al., 2015). Pelatihan yang dilakukan tim pengabdian sudah dilaksanakan dengan baik, tetapi perlu dilakukan evaluasi lanjutan seperti cross check perencanaan kurikulum sekolah sehingga lebih terarah dan tujuan pendidikan di sekolah tersebut tercapai secara optimal dengan memperhatikan kebutuhan anak. Seperti halnya yang disampaikan oleh (Hambali, 2019) bahwa perencanaan kurikulum adalah suatu proses dalam menentukan tujuan yang diinginkan dan menentukan bahan dan sumber daya yang dibutuhkan agar efisien dan efektif. Pendampingan yang dilakukan secara insentif 
dan komunikatif baik secara daring ataupun luring akan menjadi sangat efektif dan untuk memonitor bagaimana efektiftas dan manfaat yang dirasakan oleh guru (Basuki, 2016; Giyarsih, 2021). Pendampingan ini membuat guru lebih semangat dalam mencapai tujuan pendidikan yang lebih optima dan terarah sehingga lebih efektif dan efisien di TK Aulia Surakarta.

\section{CONCLUSION}

Pelaksanaan pengabdian pada guru TK Aulia Surakrata telah berjalan dengan baik dan lancar. Pelatihan guru TK pada pengabdian ini menunjukkan bahwa pelatihan yaitu pemaparan ahli, diskusi, hingga tanya jawab berjalan baik sehingga guru TK dapat menghadapi permasalahan mengenai manajemen kurikulum yang selama ini dijalankan. Pendampingan yang berupa penerapan dan monitoring manaemen kurikulum PAUD pada pengabdian ini telah terlaksana pada saat perencanaan kurikulum yang dilakukan oleh guru dan pada saat pelaksanaan pembelajaran, menunjukkan bahwa guru TK lebih memahami pengelolaan dan penataan manajemen kurikulum PAUD sehingga dapat mencapai tujuan pendidikan lebih otpimal secara efektif dan efisien.

\section{REFERENCES}

Aji, W. (2016). Himpaudi: 8 Masalah Pendidikan Anak Usia Dini. In 10 Maret.

Aprinawati, I. (2017). Penggunaan Media Gambar Seri Untuk Meningkatkan Kemampuan Berbicara Anak Usia Dini. Jurnal Obsesi : Jurnal Pendidikan Anak Usia Dini, 1(1), 12-18. https://doi.org/10.31004/obsesi.v1i1.33.

Basuki, B. (2016). Implementasi Program Akselerasi (Studi Kasus) Di SD Muhammadiyah Sapen Yogyakarta. Jurnal Akuntabilitas Manajemen Pendidikan, 4(1), 47. https://doi.org/10.21831/amp.v4i1.8198.

Ekberg, S., Danby, S., Houen, S., Davidson, C., \& Thorpe, K. J. (2017). Soliciting and pursuing suggestions: Practices for contemporaneously managing student-centred and curriculum-focused activities. Linguistics and Education, 42, 65-73. https://doi.org/10.1016/j.linged.2017.07.007.

Giyarsih, G. (2021). Peningkatan Motivasi Melaksanakan Penelitian Tindakan Kelas bagi Guru Matematika SMK melalui Workshop. Ideguru: Jurnal Karya Ilmiah Guru, 6(2), 169175. https://doi.org/10.51169/ideguru.v6i2.190.

Halim Yustiyawan, R., Supriyanto, A., \& Mustiningsih. (2016). Hubungan Pengembangan Karir, Kompetensi Profesional, Dan Motivasi Kerja Dengan Kinerja Guru Paud Di Kecamatan Driyorejo Kabupaten Gresik. Jurnal Pendidikan: Teori, Peneltian Dan Pengembangan, $1(7)$,

1297-1304. https://doi.org/http://dx.doi.org/10.17977/jp.v1i7.6545.

Halimah, S. (2020). Manajemen pengembangan kurikulum Pendidikan Agama Islam di MTs Irsyadul Islamiyah Rokan Hilir. Tarbiyah Islamiyah: Jurnal Ilmiah Pendidikan Agama Islam, 10(1), 47-59.

Hambali, A. S. \&. (2019). Menggagas Perencanaan Kurikulum Sekolah Unggul. As-Sabiqun, 3(1), 29-54. https://doi.org/10.36088/assabiqun.v1i1.161.

Hasanah, I. (2015). Kurikulum Pendidikan Anak Usia Dini. Konstruktivisme: Jurnal $\begin{array}{llll}\text { Pendidikan } \& \text { Pembelajaran, } & 7(2),\end{array}$ https://doi.org/10.30957/konstruk.v7i2.314.

Hasyim, S. L. (2015). Pendidikan Anak Usia Dini (PAUD) dalam Perspektif Islam. Jurnal Lentera: Kajian Keagamaan, Keilmuan Dan Teknologi, 1(2), 217-226. https://doi.org/10.29313/tjpi.v6i2.3195. 
Ismawati, D., \& Prasetyo, I. (2021). Efektivitas Pembelajaran Menggunakan Video Zoom Cloud Meeting pada Anak Usia Dini Era Pandemi Covid-19. Jurnal Obsesi : Jurnal Pendidikan Anak Usia Dini, 5(1), 665-675. https://doi.org/10.31004/obsesi.v5i1.671.

Ita, E. (2018). Manajemen pembelajaran pendidikan anak usia dini di TK Rutosoro Kecamatan Golewa Kabupaten Ngada Flores Nusa Tenggara Timur. Jurnal Dimensi Pendidikan Dan Pembelajaran, 6(1), 45-52.

Janus, M., \& Brinkman, S. (2010). Evaluating early childhood education and care programs. International Encyclopedia of Education, 25-31. https://doi.org/10.1016/B978-0-08044894-7.01197-0.

Kilile, J. M., Mwalw'a, S. N., \& Nduku, E. (2019). Challenges Facing Early Childhood Development Education Centres in the Implementation of the Competency Based Curriculum in Mwingi West Sub- County, Kitui County. International Journal of Education Theory and Practice, 2(3), 36-37.

Lorente, L. M. (2017). Implementation of Early Childhood Physical Activity Curriculum (SPARK) in the Central Valley of California (USA). Procedia - Social and Behavioral Sciences, 237(June 2016), 319-325. https://doi.org/10.1016/j.sbspro.2017.02.097.

Mertala, P. (2019). Digital technologies in early childhood education-a frame analysis of preservice teachers' perceptions. Early Child Development and Care, 1-8. https://doi.org/10.1080/03004430.2017.1372756.

Nurdin, N., \& Anhusadar, L. O. (2020). Evaluasi Pelaksanaan Standar Proses di Satuan Pendidikan Anak Usia Dini. Jurnal Obsesi : Jurnal Pendidikan Anak Usia Dini, 4(2), 982-993. https://doi.org/10.31004/obsesi.v4i2.485.

Pinyoanuntapong, S. (2013). The Development of Thai Early Childhood Education Curriculum to Promote Desirable Characteristics of Preschool Children. Procedia - Social and Behavioral Sciences, 88, 321-327. https://doi.org/10.1016/j.sbspro.2013.08.512.

Rahelly, Y. (2018). Implementasi Kurikulum 2013 Pendidikan Anak Usia Dini (Paud) Di Sumatera Selatan. JPUD - Jurnal Pendidikan Usia Dini, 12(2), 381-390. https://doi.org/https://doi.org/10.21009/JPUD.122.21.

Rasib, A. (2016). Pendekatan Kolaboratif dalam Pembelajaran Tematik Terpadu di Kelas III Sekolah Dasar Negeri 21 Kuala Mandor B. Universitas Tanjungpura.

Ruder, E. H., \& Lohse, B. A. (2017). NEEDs for Tots: A Teacher-Ready and Parent-Friendly Curriculum Focuses on Principles of the Satter Division of Responsibility in Feeding. Journal of Nutrition Education and Behavior, 49(4), 357-359.e1. https://doi.org/10.1016/j.jneb.2016.12.011.

Sanders-Smith, S. C., Lyons, M. E., Sylvia Ya-Hsuan, Y., \& McCarthey, S. J. (2021). Valuing relationships, Valuing differences: Co-teaching practices in a Hong Kong early childhood center. Teaching and Teacher Education, 97, 103230. https://doi.org/10.1016/j.tate.2020.103230.

Sarinah, S., Febrini, D., \& Syarifin, A. (2018). Bagaimana Manajemen Kurikulum Pendidikan Anak Usia Dini Di Ra Al-Haq Pematang Gubernur Kota Bengkulu. Al Fitrah: Journal Of Early Childhood Islamic Education, 2(1), 180-199. https://doi.org/10.29300/alfitrah.v2i1.1515.

Septiani, G. (2018). Manajemen Kurikulum dan Pembelajarannya di TK ABA Gendingan, Kalasan (Aliran Muhammadiyah). Jurnal Kajian Perkembangan Anak Dan Manajemen Pendidikan Usia Dini, 1(1), 37-51.

Sugiyanto, S., Kartowagiran, B., \& Jailani, J. (2015). Pengembangan Model Evaluasi Proses Pembelajaran Matematika Di Smp Berdasarkan Kurikulum 2013. Jurnal Penelitian Dan Evaluasi Pendidikan, 19(1), 82-95. https://doi.org/10.21831/pep.v19i1.4558.

Suminah, E., Nugraha, A., Lestari, G. D., Mareta, \& Wahyuni, M. (2015). Kurikulum 
Pendidikan Anak Usia Dini. Apa, Mengapa, dan Bagaimana. Direktorat Pembinaan Pendidikan Anak Usia Dini.

Suryawan, M. J., \& Romadi, R. (2018). Komparasi Pelaksanaan Kurikulum 1994 dan Kurikulum 2006 pada Mata Pelajaran Sejarah (Studi Kasus di Sekolah Menengah Atas (SMA) di Magelang). Indonesian Journal of History Education, 6(1), 66-75. https://journal.unnes.ac.id/sju/index.php/ijhe/article/view/27355.

Upshur, C. C., Wenz-Gross, M., Rhoads, C., Heyman, M., Yoo, Y., \& Sawosik, G. (2019). A randomized efficacy trial of the second step early learning (SSEL) curriculum. Journal of Applied Developmental Psychology, 62(February), 145-159. https://doi.org/10.1016/j.appdev.2019.02.008.

Utami, W. Y. D., Jamaris, M., \& Meilanie, S. M. (2020). Evaluasi Program Pengelolaan Lembaga PAUD di Kabupaten Serang. Jurnal Obsesi : Jurnal Pendidikan Anak Usia Dini, 4(1), 67-76. https://doi.org/10.31004/obsesi.v4i1.259.

Watini, S. (2019). Pendekatan Kontekstual dalam Meningkatkan Hasil Belajar Sains pada Anak Usia Dini. Jurnal Obsesi: Jurnal Pendidikan Anak Usia Dini, 3(1), 82-90. https://doi.org/10.31004/obsesi.v3i1.111. 